\title{
Recent Trends in Japanese Mathematics Textbooks for Elementary Grades: Supporting Teachers to Teach Mathematics through Problem Solving
}

\author{
Akihiko Takahashi \\ College of Education, DePaul University, USA
}

Copyright (C) 2016 by authors, all rights reserved. Authors agree that this article remains permanently open access under the terms of the Creative Commons Attribution License 4.0 International License

\begin{abstract}
Problem solving has been a major theme in Japanese mathematics curricula for nearly 50 years. Numerous teacher reference books and lesson plans using problem solving have been published since the 1960s. Government-authorized mathematics textbooks for elementary grades, published by six private companies, have had more and more problem solving over the years. As a result, almost every chapter in Japanese mathematics textbooks for elementary grades begins with problem solving as a way to introduce students to new concepts and to introduce new procedures. But a large wave of teacher retirement in recent years has left newly hired teachers without the collegial support they need to develop the expertise to teach through problem solving. In order to overcome this challenge, the latest edition of a major mathematics textbook series in Japan includes more resources to help teachers teach through problem solving and to help students learn through problem solving. The book contains more alternative approaches to a problem, provides diagrams meant to help students solve problems independently, and includes pages that teach students how to take notes effectively. By comparing the latest two editions of this textbook series, the author will highlight how the text has increased its support of problem solving, and will relate the changes to recent trends of Japanese mathematics textbook designs.
\end{abstract}

Keywords Japan, Problem Solving, Alternative Approaches

\section{Emphasis on Problem Solving in Japanese Mathematics Education and Its Impacts}

Problem solving has been a major focus in Japanese mathematics curricula for nearly half a century. Numerous teacher reference books and lesson plans using problem solving have been published since the 1960s. By early 1990 s approaches for teaching mathematics using problem solving had been established among Japanese elementary school teachers.

There are several notable characteristics of the mathematics classroom instruction focused on problem solving in Japan. First, Japanese teachers have tried to use problem solving for students to develop concepts and understanding of mathematics, and acquire skills to learn and use mathematics. Therefore problem solving is not viewed as an end-of-the-chapter activity that is solely focused on developing problem-solving skills and strategies. Instead, the approach has been used throughout the curriculum as a process of learning mathematics. Second, Japanese problem solving lessons usually do not end even after each student finds a solution(s) to the problem. Japanese teachers facilitate extensive discussions with students by comparing and highlighting the similarities and differences among students' solution approaches in order for students to learn something new. Japanese teachers believe that the heart of the lesson begins after students come up with a solution(s).

As teaching though problem solving gradually spread to more schools and districts in Japan, Japanese textbooks began to include ideas from the study of teaching through problem solving. For example, textbooks included open-ended questions for guiding students to develop understandings, instead of explanations of the concepts and the procedures. Watanabe (1) examined some of the pages from 1958, 1968, 1977, 1989, 1999, and 2008 editions of Japanese elementary mathematics textbooks and found that the editions after 1989 shared some similarities that are distinct from the previous three editions. These similarities include:

- The opening problems in the units appear on the right-hand page of the book and only the problem is on the initial page, and the following page includes multiple approaches to the problem solution and 
designed to support discussion of a variety of approaches to the solution, and

- Inclusion of more open-ended questions and suggestions by cartoonlike characters, moving away from providing clear explanations of the concepts and procedures to expecting the students to investigate mathematics using their own reasoning based on their prior learning.

These differences before and after 1989 editions appear to be in alignment with the implementation of teaching through problem solving approach. By early 1990s almost every chapter in Government-authorized mathematics textbooks for elementary grades, published by six private companies, began with problem solving as a way to introduce students to new concepts, and even to procedures (2-4).

In summary, the classroom instruction of Japanese mathematics classrooms at least in elementary grades have gradually shifted to teaching through problem solving decades ago and the government authorized textbooks also shifted to support teachers and students to use problem solving as a major approach for teaching and learning mathematics.

\section{Current Issues in Teaching Mathematics in Japan}

Although the successful shift to teaching through problem solving during 1980s to 1990 s, and Stigler and Hiebert argued that Japanese mathematics classrooms exemplify the ideas of reform mathematics classrooms (3), current Japanese novice teachers have two major challenges to teach mathematics using teaching through problem solving; one is adequate knowledge for teaching the contents, and another is the lack of collegial support by experienced teachers.

The Ministry of Education, Culture, Sports, and Technology released the 2008 Course of Study (COS), the national curriculum, in response to concerns about declining mathematics achievement due to a severe reduction in the content and number of class periods in the 1998 revision. The 2008 COS re-aligned itself to the content and the number of class periods of the 1989 COS. This change requires an additional $20 \%$ of mathematics content in grades 1-6. This content increase mostly impacts teachers with less than 10 years of teaching experience. For those teachers who previously taught according to the $1989 \mathrm{COS}$, this change presented little challenge because the new contents were mostly taught under the 1989 COS. On the other hand, younger teachers see this revision as an overwhelming increase to their workload and it includes some mathematics they may never have taught before.

Another challenge is due to a large wave of teacher retirement in recent years. Based on a Ministry report (2013), Japanese elementary schools have been experiencing a radical demographic transition. Moreover, it is expected that about $37 \%$ of elementary school teachers will be at the retirement age of 60 years in the next ten years.

This recent change in the schools has left newly hired teachers without the collegial support of experienced teachers necessary to develop skills needed to teach through problem solving.

In addition to the above major challenges, the $2008 \mathrm{COS}$ increased the emphasis on mathematical processes such as thinking mathematically and expressing thoughts and ideas using mathematical representations such as diagrams and equations. In order to address these new concepts, all classroom teachers are expected to regularly provide each student with opportunities to think mathematically and to express their own thoughts.

In order to implement the new COS, Japanese teachers, especially those who have had less than 10 years of experience, need to consider not only how the amount of content has changed but also how to design lessons that will push all students to think mathematically and to communicate their ideas in such a way as to learn multiple ways of thinking mathematically.

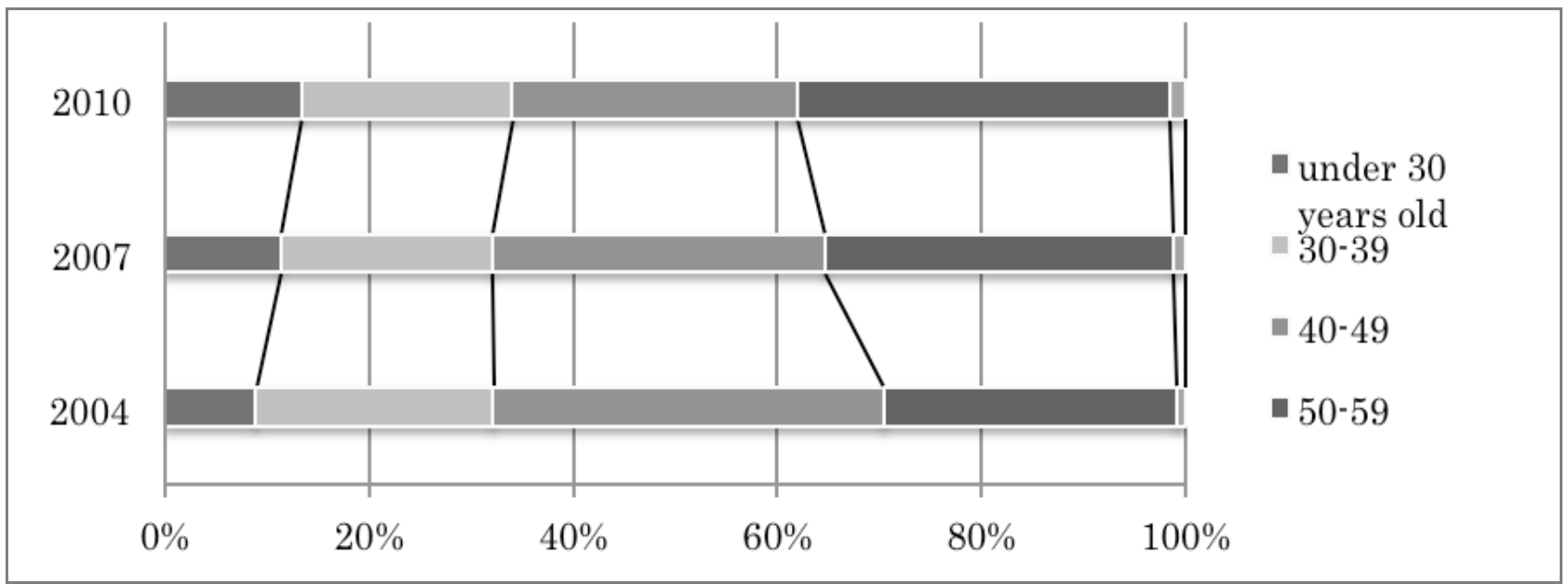

(Source: Ministry of Education, Culture, Science \& Technology in Japan, 2013)

Figure 1. Percentage of Full-Time Teachers by Age in Elementary Schools 


\section{The Textbook Updates}

In order to overcome the above challenges, the latest edition of a major mathematics textbook series in includes more resources to assist teachers in their instruction via problem solving and to help students to learn through problem solving. The book-series contains more alternative approaches for solving a problem, provides diagrams meant to help students solve problems independently, and includes separate pages that teach students how to take notes effectively.

The following section will highlight how the text has increased its support of problem solving, and relate the changes to recent trends of Japanese mathematics textbook design by comparing the latest two editions of the best-selling elementary mathematics textbook series-the 2006 edition and the 2011 edition.

In order to highlight such changes, pages using similar problems have been compared. The problems are typical of those found in Japanese mathematics textbooks for 4th grade; they are presented to students who have learned the formulas for finding the area of rectangles and squares. (See Figure 2 and 3) The objective is for students to understand how they might use formulas, which they have learned previously, to find the area of unfamiliar shapes. In order to use their prior knowledge to find the area of these new shapes, the students should use strategies like area-preserving transformations (cutting and re-arranging) or area-doubling transformations (copying and re-arranging). Thus, the teachers should be able to use this problem to help students learn general strategies for using previously-learned area formulas to find the area of unfamiliar shapes (5).

Although both pages are designed for teachers to introduce the strategies to use the area formulas though problem solving and use very similar problems, the contents of the pages are very different. For example, the total number of pages that are assigned for a particular concept varies. The 2006 edition uses only one page including two exercise problems. On the other hand, the 2011 edition uses three pages, page B25, B26, and B27 with one exercise problem. Although both editions expect teachers to use the pages for one 45-minute-lesson, the contents in the 2011 edition include more directions and diagrams. For example, the 2006 edition includes only two major directions:

1) Write the ways to find the area using the following diagrams.

2) Calculate the area in several ways.

It is clear that these directions are asking students to find the area of the shape in several different ways. These key directions may be enough for experienced teachers to facilitate a fruitful discussion in order to support students in accomplishing the goals of the lesson. However, novice teachers may have difficulty in teaching through problem solving and could end up using more teacher-centered approaches such as teaching-by-telling (2). 


\section{Finding the area of composite figures}

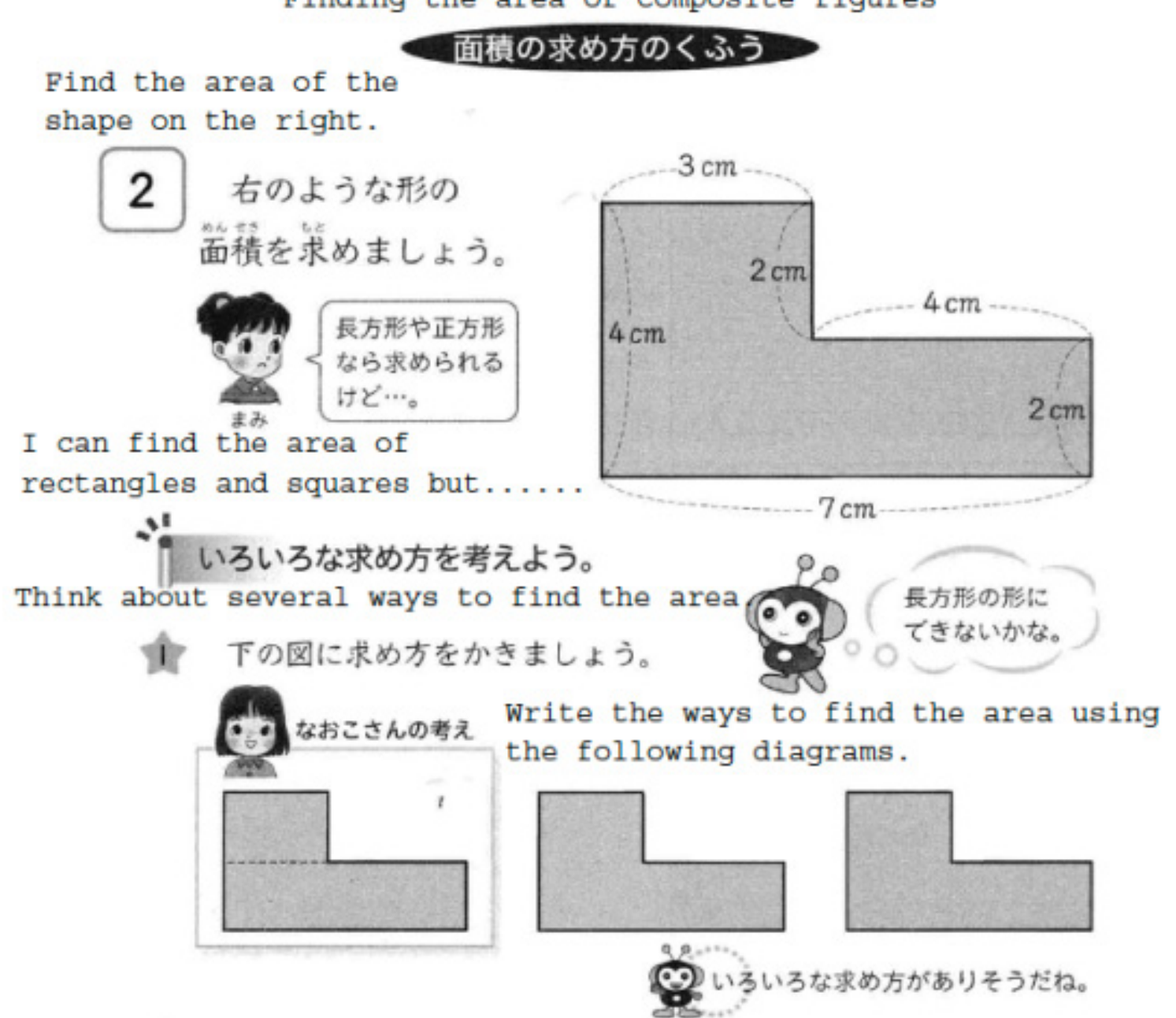

2 いろいろな求め方て, 面栍を計算しましょう。 Calculate the area in several ways.

答えをたしかめう。

Find the area of each shape below in several different ways? 5 下のような形の面積を, いろいろな方法で求めましょう。

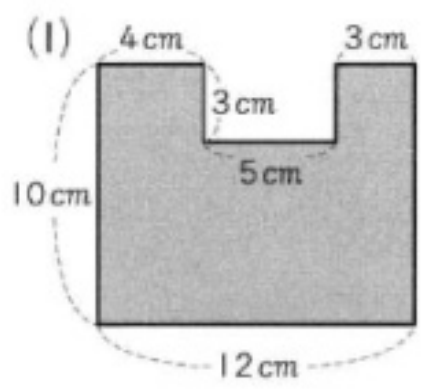

(2)

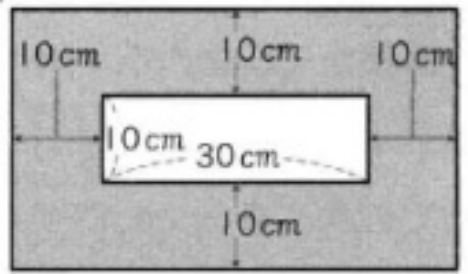

58

Figure 2. Reprint from Sugiyama et al. (2006) Mathematics Textbooks for Elementary Grade 4th grade, p.58. Reprint with permission from Tokyo Shoseki Publishing Co. The English translations are added by the author. 
On the other hand, the 2011 edition includes following five directions:

1) Write down the way you thought about doing it using pictures and math sentences.

2) Write down the way you thought about doing it using pictures and math sentences.

3) Look at the math sentence Takumi wrote and explain how he thought about the problem.

4) Look at the math sentence Yumi wrote on the next page and explain how she thought about the problem.

5) What idea is common among the three students?

Different from the directions in the 2006 edition, these include what students can do by looking at other approaches for finding the area of the same shape. In order to do so, the textbook pages include more diagrams and/or equations of alternative approaches.

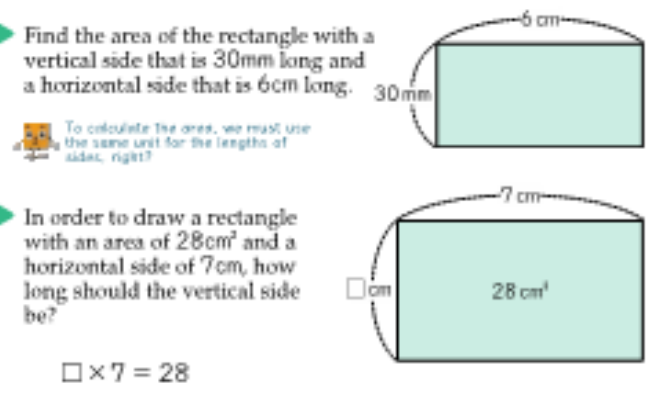

Figures $(\mathrm{A}, \mathrm{B}$, and $\mathrm{D}$ on page 22 are rectangles and a square that all have perimeters of $20 \mathrm{~cm}$. In the table below, summarize the areas and the length of vertical and borizontal sides of the rectangles and square with the perimeters of $20 \mathrm{~cm}$.

\begin{tabular}{|c|c|c|c|c|}
\hline & 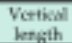 & 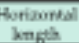 & Ares & Permimeter \\
\hline (A) & 4 & 6 & & \\
\hline (8) & 5 & 5 & & \\
\hline \multirow[t]{3}{*}{8} & 3 & 7 & & \\
\hline & 2 & & & \\
\hline & 1 & & & \\
\hline
\end{tabular}
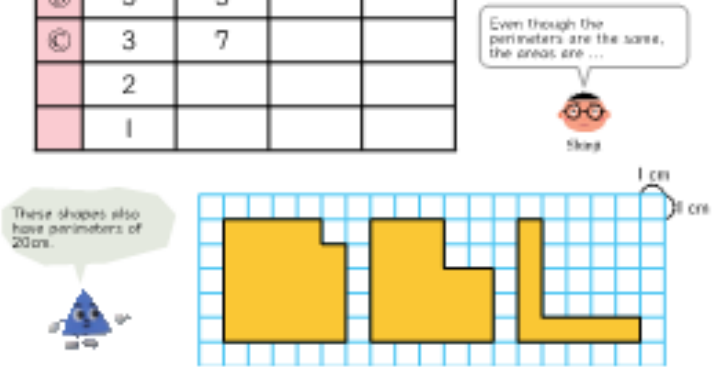

62

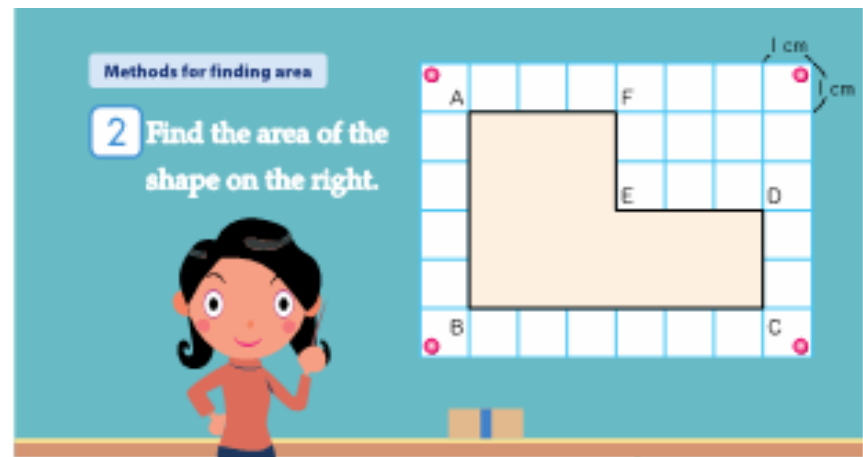

? Let's think about how we can calculate the area of shapes likee

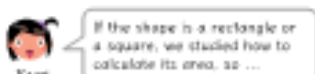

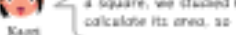

Write down the way you thought about doing it using pictures and math sentences.

A. Une the cards on
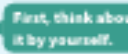

lecterementies.

merluse kemed

in bxyouran we?

Wric thes ins

may this ether
pagkean

Paderotian tien
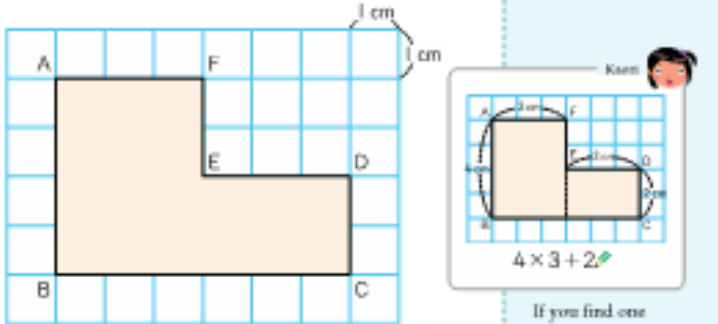

If you find one way, try to tind ancther way. 


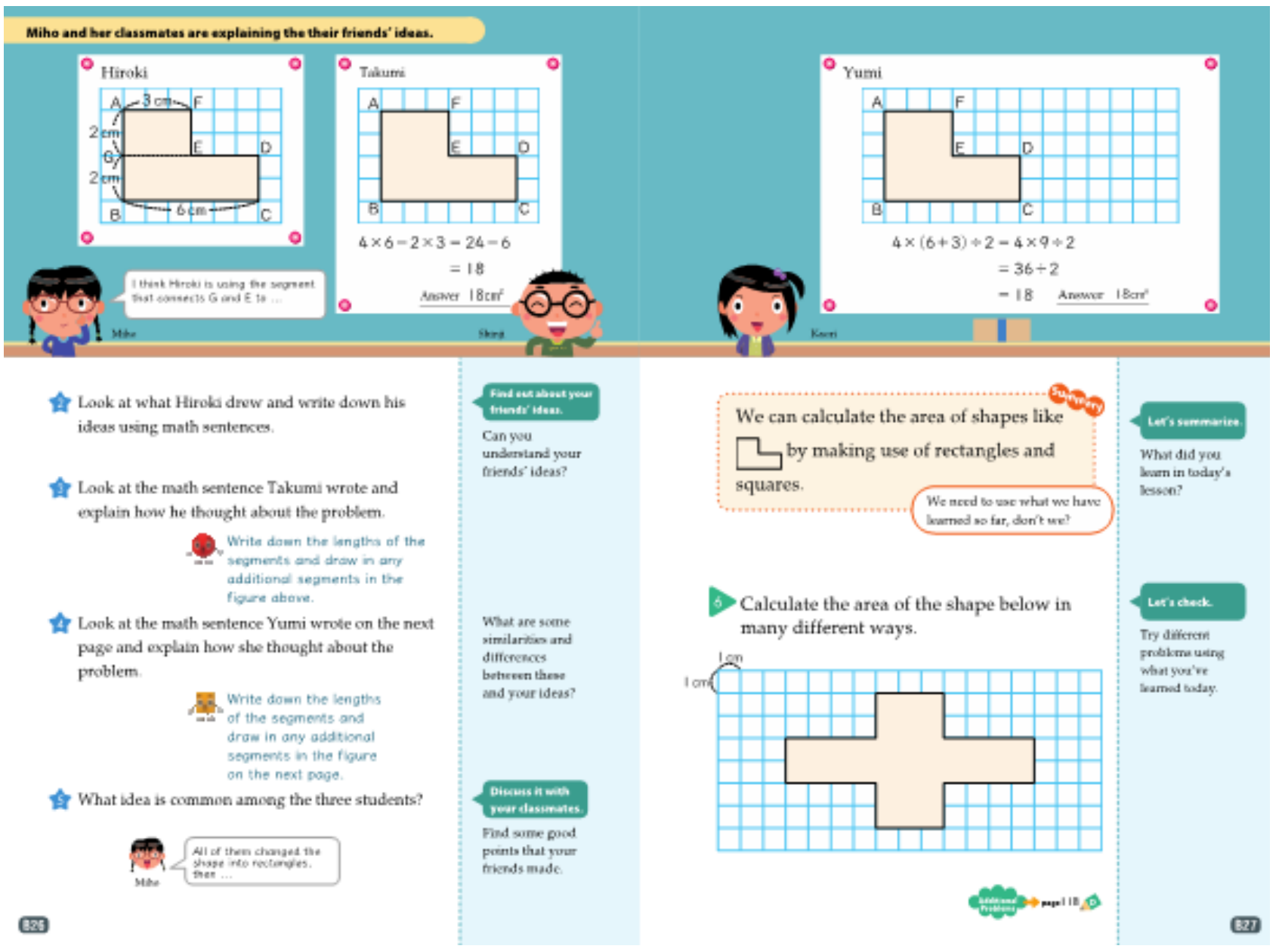

Figure 3. Reprint from Fujii, T. \& Iitaka, S. (2012). Mathematics International Grade 6. Tokyo, Japan: Tokyo Shoseki, Grade 4 th grade, pp.85- 87. www.globaledresources.com; Reprint with permission from Tokyo Shoseki Publishing Co.

Another major change made for the 2011 edition was to include special pages to support students in developing note-taking skills throughout the grades. Starting during grade 2, each textbook includes some examples of how to take notes to foster students' mathematical thinking and problem solving skills. Appendix 1 shows the pages entitled "My Math Notes" which incorporates the contents of the area lesson to demonstrate how to organize notes when focusing on problem solving.

\section{Summary}

Japanese educators have been using textbooks as a resource for teaching mathematics. Thus, they often emphasize that they can distinguish between "teaching the textbook" and "using the textbook to teach mathematics." In order to provide a better learning experience for their students, all the teachers should be able to use the textbook to teach mathematics effectively using their knowledge and expertise for teaching mathematics. This statement is still widely accepted in Japan; however, textbook publishers have responded to demographic shifts and are designing the textbooks with new supports to help less-experienced teachers teach mathematics through problem solving.

It may now be important to investigate whether these changes in textbook design actually have the desired impacts on instruction and teacher growth.

\section{Appendix}

Reprint from Fujii, T. \& Iitaka, S. (2012). Mathematics International Grade 6. Tokyo, Japan: Tokyo Shoseki, Grade 4th grade, pp.90-91. www.globaledresources.com Co. 


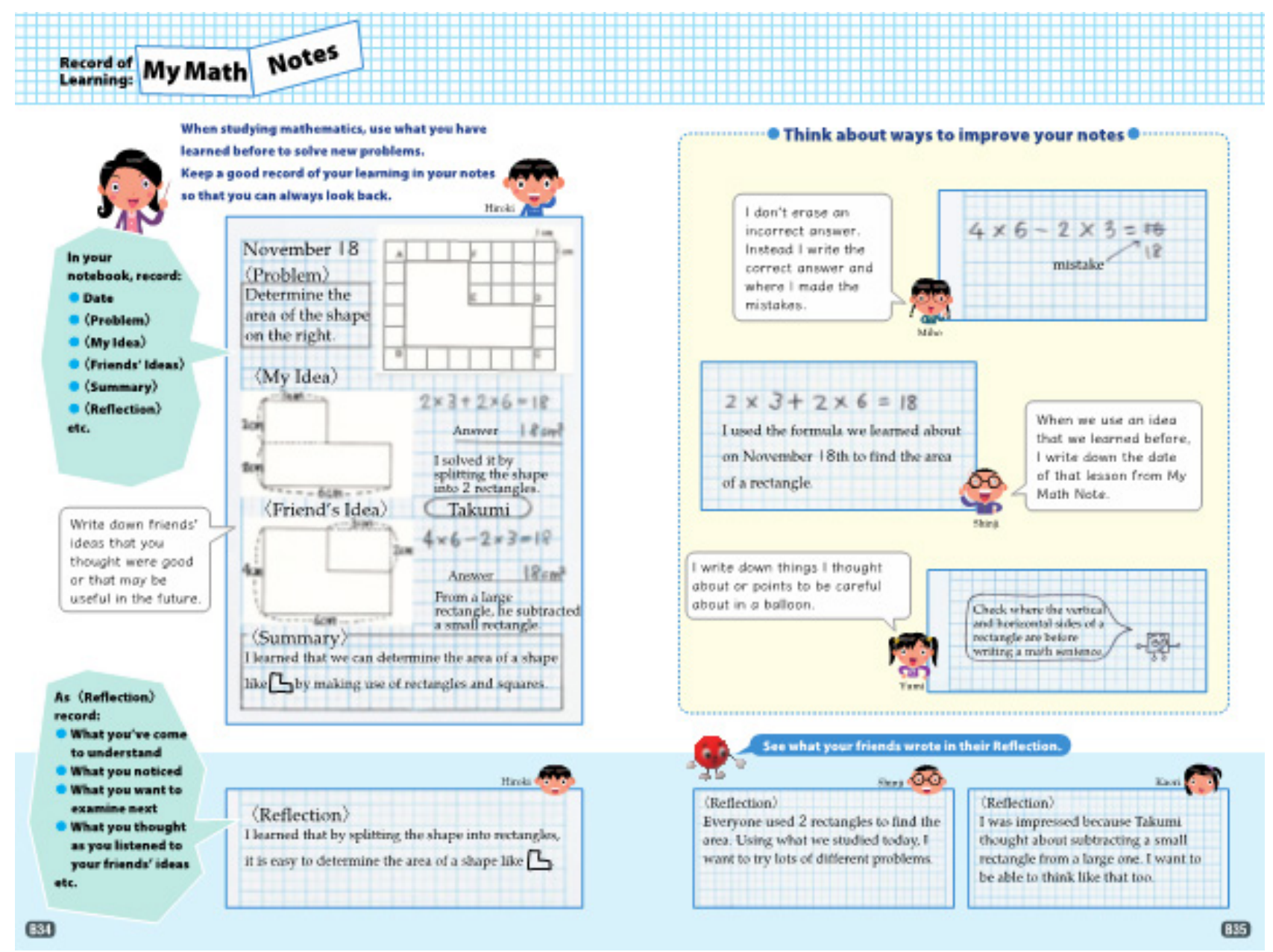

\section{REFERENCES}

[1] Watanabe T. Transformation of Japanese elementary mathematics textbooks: 1958-2012. In: Li Y, Silver E, Li S, editors. Transforming mathematics instruction: Multiple approaches and practices. Heidelberg: Springer; 2014. p. 199-216.

[2] Takahashi A. The Japanese approach to developing expertise in using the textbook to teach mathematics rather than teaching the textbook. In: Li Y, Kaiser G, editors. Expertise in

Mathematics Instruction: An international perspective. New York: Springer; 2011a. p. 197-219.

[3] Stigler J, Hiebert J. The teaching gap: Best ideas from the world's teachers for improving education in the classroom. New York: Free Press; 1999.

[4] Takahashi A. Current trends and issues in lesson study in Japan and the United States. Journal of Japan Society of Mathematical Education. 2000;82(12):15-21.

[5] Watanabe T, Takahashi A, Yoshida M. Kyozaikenkyu: A critical step for conducting effective lesson study and beyond. In: Arbaugh F, Taylor PM, editors. Inquiry into Mathematics Teacher Education, Association of Mathematics Teacher Educators (AMTE) Monograph Series 52008. p. 131-42. 